\title{
Halitosis: A mirror of systemic and oral health
}

\author{
Dr. Anupama S Rao ${ }^{1}$ Dr. Vijaya Kumar ${ }^{2}$ \\ ${ }^{I}$ (Department of Periodontics, Yenepoya Dental College/Yenepoya University, India \\ 2 (Department of Public Health Dentistry, Yenepoya Dental College/Yenepoya University, India
}

\begin{abstract}
Halitosis is known as unpleasant oral odor affecting large proportion of population and may be the cause of a significant social and psychological handicap. People who are not aware of their bad breath may encounter romantic, social and professional rejection without knowing the reason. $85 \%$ cases of halitosis originate from microbial putrefaction within the oral cavity itself. Modern analytical and microbiological techniques permit diagnosis of halitosis. Management of oral malodor is directed at managing and reducing the bacterial load from oral cavity by instituting proper oral hygiene measures, control of tongue flora by brushing or scraping, and possibly the adjunctive use of antiplaque agents.
\end{abstract}

Keywords - : Chlorhexidine, oral malodor, organoleptic rating, tongue coatings, volatile Sulphur Compounds.

\section{Introduction}

The term halitosis originated from the Latin word halitus means breath, and the Greek - osis, is an unpleasant condition experienced by most of individuals.[1] since bad breath usually comes from mouth itself, the dentist should be the first professional whom patients seek help. In recent years, there has been a growing awareness that oral malodor is a problem that dental profession should recognize and address. Other terminologies used for halitosis are bad breath, oral malodor, fetor-oris, and fetor ex-ore. [2] Halitosis is essentially a symptom of underlying local or systemic conditions rather than a distinct disease entity.

Oral malodor may rank only behind dental caries and periodontal disease as the cause of patient's visits to the dentist; still it is a recognizable condition that deserves professional attention. 85\% cases of halitosis originate from microbial putrefaction within the oral cavity itself, and the volatile sulphur compounds have been cited as the predominant source of halitosis which is generated within the oral cavity from various reservoirs of bacteria (dorsum of tongue, periodontal pocket, dental caries, dentures etc). Various devices have been developed to assess oral malodor and many methods applied in an attempt to reduce the amount of gases released by bacteria in the oral cavity.

The aim of the present article is to summarize general concept related to bad breath and express the psychological aspects along with various etiological, diagnostic and treatment modalities of halitosis.

\section{Psychosomatic aspects of halitosis}

Patients with psychosomatic halitosis are categorized in to two subgroups, 1) patients who have "imaginary halitosis" without detectable oral malodor and 2) patients who suffer from oral malodor with accompanying psychosomatic tendencies. In the former case patient does not accept the fact that he or she has no offensive bad breath. In the latter case a patient may not believe that his or her oral malodor is reduced after treatment and may continue to complain about the "halitosis "that does not exist any longer. Psychosomatic conditions should be well addressed as it results in self criticism, inferiority complex, social phobia, poor self esteem. [3]

\section{Classification}

The various types of oral odor given by Crispian Scully includes[4]

\subsection{Morning breath}

Oral malodor is common on awakening (morning breath) usually as a consequence of low salivary flow and stagnation of saliva during sleep.

\subsection{Exogenous Malodor}

Halitosis at other times of the day is often the consequence of eating various foods or habits such as smoking or drinking alcohol

\subsection{True oral malodor (Endogenous malodor)}

It is often a consequences of Volatile Sulphur Compounds released due to anaerobic bacterial activity in oral cavity.

3.4 Halitosis due to systemic causes like diabetes, kidney failure, lung abscess etc

3.5 Drugs like Phenothiazines, Cytotoxic drugs, Nitrates, Nitrites etc

3.6 Psychogenic Malodor 
This is a group of patients who are by no means have any evidence of halitosis that can be detected even with objective testing and the halitosis may be attributable to a form of delusion of mono-symptomatic hypochondriasis (self-halitosis; halitophobia).

\subsection{Oral causes}

\section{Etiopathogenesis:}

As many as $85 \%$ of patients with bad breath the odor migrates in mouth. The relationship between bacterial putrefaction and oral malodor has been shown in the [Fig 1][5] oral causes includes periodontal diseases, ulcers, tongue coatings, dental caries likewise there are various factors have been shown to be associated with halitosis but selective relationship is not established.[6]

\subsection{Extra oral causes}

It includes various systemic diseases[7] (Table1), Drugs[7](Table2), starvation, xerostomia etc. All together non- oral causes affect a very small percentage of people experiencing oral malodor.

\section{Factors involved in intraoral halitosis}

Halitosis is caused by presence of odorous gases in the air expelled from oral cavity. The odorous compounds are mainly divided into

\subsection{Sulphur containg gases(VSCs)}

5.1.1 Hydrogen Sulphide

5.1.2 Methyl Mercapton

5.1.3 Methyl Sulphide

5.1.4 Dimethyl sulphide

\section{$5.2 \quad$ Non-sulphur compounds}

5.2.1 Volatile aromatic compounds

5.2.2 Organic acid(acetic and propionic acids)

5.2.3 Amines(putrescine,cadeverine)

\section{Role of Tongue coating}

Recently, the dorsal surface of the tongue has been identified as the primary

source of oral malodor in both periodontally diseased and healthy individuals. This is attributed to a large surface area of the tongue and its papillary structure which retain considerable amounts of desquamated epithelial cells and dead leukocytes. [8]

\section{Association between Halitosis and Periodontal Disease}

The ratio of methyl mercaptan/ hydrogen sulphide increased in mouth air from patients with periodontal disease when compared to healthy individuals. Odor scores were significantly correlated with the concentration of overall bacterial populations and that higher levels of crevicular bacteria were associated with greater odor scores. VSCs concentration in mouth air increases with total pocket depth and increased bleeding index. [9]

\section{Diagnosis}

Proper diagnosis is essential to intelligent treatment. An accurate diagnosis can be achieved by analyzing the data collected from the patient's history, clinical examination and interpretation of any laboratory tests.

Complains of bad breath should be taken seriously by the dentist, regardless whether they appear justified when the patient expresses concern about his or her breath, it is important to set up a special appointment for an assessment. Formulation of diagnosis of halitosis is shown in [Table3]

\subsection{Physical Examination}

Much as in any other diagnosis, patient history and physical examination are valuable tools. Patient complaining halitosis should be ruled out extra oral causes for the same. Intra oral examination consists of assessment of all abnormal findings of soft tissue, hard tissue and supporting structures such as dental decay, periodontal disease, lesions present on buccal mucosa, labial mucosa, tongue, palate, vestibule and floor of the mouth of bacterial, viral and fungal origin which can contribute in the production of the malodor due to putrefaction of bacteria.

\subsection{Information provided from tests or special studies}

8.2.1Organoleptic measurement

A subjective test scored on the basis of the examiner's perception of a subject's oral malodor. Different semiquantitative scales have been used, ranging from 0 to 5. [Table 4] Before the Organoleptic assessment, both 
patient and examiner must follow some instructions in order to obtain a more reliable result. Patients are instructed to abstain from eating strong foods at least 48 hours before the assessment and patients must abstain from ingesting any food or drink, omit their usual oral hygiene practices, abstain from using oral rinse and breath fresheners, and abstain from smoking for 12 hours before the assessment. The oral malodor examiner is required to refrain from drinking coffee, tea, or juice and to refrain from smoking and using scented cosmetics before the assessment. [10]

8.2.2Gas chromatography (GC)

It is considered the gold standard for measuring oral malodor since it is specific for VSCs, the main cause of oral malodor. The GC equipment is expensive, bulky, and the procedure requires a skillful operator. Therefore, this technology has been confined to research and not to clinical use.

\subsubsection{Portable sulfide monitor}

Sulphide monitors analyses for total sulphur content of the subject's mouth air. Although compact sulphide monitors are inexpensive, portable, and easy to use, most of them are not able to distinguish among the VSCs For example, the Halimeter has high sensitivity for hydrogen sulphide but low sensitivity for methyl mercaptan which is a significant contributor to halitosis caused by periodontal disease.

8.2.4 BANA Test

It is an enzymatic test helpful in detecting halitosis by detecting the bacteria usually Porphyromonas gingivalis, Treponema denticola and Tenerella forsythus which are considered active hydrogen sulphide producers in vitro. In this technique, bacteria are identified by detecting trypsin like protease. It is available as a chair side diagnostic kit.(perioscan) [11]

8.2.5 Electronic nose system

It is an artificial nose which provides rapid, simple and quantitative odor measurement using chemical sensor. Besides volatile sulfur compound Electronic nose can also detect aromatic, amine containing and ammonia derived compounds in food beverages.[12]

\subsection{Radiographs}

Radiographs may be necessary to evaluate carious extension in the pulp of the teeth. Carious sites are sites for food retention and putrefaction. Restorations, crowns, appliances, fixed and removable prosthesis should be examined.

\subsection{Microbiologic culture and sensitivity studies}

\subsubsection{Biopsy}

Various vesiculobullous or ulcerative lesions can be source of oral malodor. Hence biopsy is essential in such lesions.

8.4.2 Culture and sensitivity tests

Culture and sensitivity tests help in identifying various infections in the oral cavity or those infections not responding to initial antimicrobial therapy.

A few healthy tips to prevent bad breath

\section{Prevention of Halitosis}

- $\quad$ Practice good oral hygiene which includes brushing twice a day with fluoridated toothpaste to prevent dental caries and plaque buildup. Use dental floss or an interdental brush once a day to remove food particles and dental plaque from embrasure areas. Clean your tongue before going to bed.

- $\quad$ Removable partial and complete dentures should be kept in water every night and cleaned thoroughly before placing in the mouth next morning.

- At least twice a year see your dentist for oral examination and professional teeth cleaning.

- Avoid smoking and other tobacco based product which can worsen oral malodor

- $\quad$ Drink lots of water to prevent dehydration and dry mouth.

- $\quad$ Keep a $\log$ of food you eat. Avoid sulphur containing food such as onions, garlic, cabbage.Dont skip meals. Have a healthy breakfast.

- Keep a regular check on your systemic health.

\section{Treatment of halitosis}

Halitosis has got a multifactorial etiology. Therefore the treatment approach should be primarily based on elimination of etiological factors. Also the best way to treat bad breath is to motivate patients to practice good oral hygiene and to ensure that their dentition is properly maintained.

\subsection{Oral hygiene maintenance includes}

Periodic and professional maintenance of oral hygiene should be done to prevent potential foci of microbial colonization. Since oral diseases are a major cause of bad breath, prompt diagnosis and treatment that includes continuous home oral hygiene measures with frequent recalls and maintenance. 
10.1.1Mechanical methods

- Tooth brushing: Brushing with toothpaste may reduce malodor for as long as two hours. Sodium bicarbonate dentifrice appears to be superior to fluoride dentifrice for the reduction of volatile sulphur compounds levels.

- Flossing: It is one of the most effective day to day home treatments that do not involve antimicrobial agents. Other interdental cleaners (such as tooth picks) also can be effective in identifying and cleaning sites of odor production.

- Tongue cleaning: To prevent tongue odor, the tongue should be cleaned in a gentle but thorough manner. The patient should be reminded that the posterior portion of the tongue is the least accessible but usually smells the worst.

10.1.2 Chemical methods

Mouth rinses may be indicated in those patients who even after maintaining good oral hygiene continue to have malodor. Many commercially available mouth rinses $(0.2 \%$ Chlorhrxidine, Two phase oil-waterrinse, Triclosan, Hydrogen peroxide, Oxidizing lozenges etc)claim to effectively eliminate malodor(Table5).[13]

10.1.3 Masking agents

Mouth spray, lozenges and chewing gums are used agents for masking bad breadth but effects of these agents' remains only for temporary period.

\section{Conclusion}

Bad breath is a major concern for many people. Because it nearly always originates from the mouth, it can and should be diagnosed and treated professionally by dentists. There is no "stand-alone" product solution for halitosis nor do traditional standards of dental or periodontal care necessarily eliminates the problem. Recent developments in the understanding of the etiologies of breath malodor have spawned new techniques for its assessment and management. Dentists and their team should focus on the philosophy of wellness, as well as patient's quality of life expectation.

\section{Diet, bacteria, epithelial cells

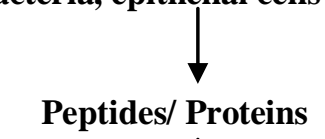

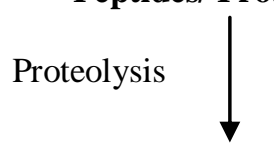

Amino acids

Aminolysis

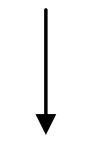

Putrefaction products

Volatile sulphur compounds

(Hydrogen Sulphide, Methyl Mercaptan)

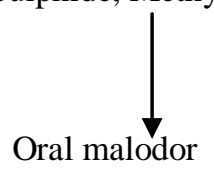

Fig1: Oral bacterial putrefaction and its relation to oral malodor ${ }^{5}$ 
Table no.1: Systemic diseases capable of producing halitosis ${ }^{7}$

\begin{tabular}{|l|l|}
\hline DISEASES & CHARACTERISTIC ODOR \\
\hline $\begin{array}{l}\text { Diabetes mellitus or } \\
\text { impending Diabetic coma }\end{array}$ & Acetone, fruity (not detected in well controlled patients) \\
\hline Liver failure (terminal stage) & $\begin{array}{l}\text { Sweetish musty, feculent "amine" odour resembling a fresh cadaver } \\
\text { known as "fetor hepaticus }\end{array}$ \\
\hline $\begin{array}{l}\text { Portocaval venous } \\
\text { anastomoses }\end{array}$ & $\begin{array}{l}\text { Same as fetor hepatic us but characteristically intermittent in nature } \\
\text { for long period of time }\end{array}$ \\
\hline $\begin{array}{l}\text { Lung abscess, tuberculosis, } \\
\text { bronchiectasis }\end{array}$ & Foul, putrefactive \\
\hline Blood dyscrasias & Resembling decomposed blood of a healing surgical extraction wound \\
\hline Liver cirrhosis & Resembling decayed blood \\
\hline Uremia, kidney failure & Ammonia or urine \\
\hline $\begin{array}{l}\text { Toxemia, G.I. disorder, neuro } \\
\text { psychiatric }\end{array}$ & Varies: poor oral hygiene intensifies the odour. \\
\hline $\begin{array}{l}\text { Fever, dehydration, } \\
\text { Macroglobulinemia (with } \\
\text { salivary gland involvement). }\end{array}$ & $\begin{array}{l}\text { Odor mainly due to Xerostomia with poor oral hygiene and / or toxic } \\
\text { waste byproducts accumulated in the body. }\end{array}$ \\
\hline $\begin{array}{l}\text { Syphilis, exanthematous } \\
\text { disease, granuloma venereum }\end{array}$ & Fetid \\
\hline Wegcners granulomatosis & Necrotic, putrefactive \\
\hline
\end{tabular}

Table no 2: Halitosis systemic administration of drugs

\begin{tabular}{|l|l|l|}
\hline Drug & Main therapeutic use & Mechanism \\
\hline Insosorbide dinitrate & Anginal therapy & $\begin{array}{l}\text { Both intrinsic odor of the drug and } \\
\text { metabolic end products of the } \\
\text { drug }\end{array}$ \\
\hline Ethyl alcohol & Anginal therapy, sedation & $\begin{array}{l}\text { Odor of the drug reaches the } \\
\text { breath via the systemic route }\end{array}$ \\
\hline Chloral hydrate & Hypnotic sedation & \\
\hline Antihistamines & Allergy, sedation & \\
\hline Antineoplastics & Cancer therapy & $\begin{array}{l}\text { Antihypertension, } \\
\text { antiedematic }\end{array}$ \\
\hline Diuretics & $\begin{array}{l}\text { Schizophrenia, antiemitics, } \\
\text { psycho sedative }\end{array}$ & Due to xerostomia caused by drug \\
\hline $\begin{array}{l}\text { Phenothiazine and their } \\
\text { derivatives }\end{array}$ & Sedation \\
\hline Tranquilizers & \\
\hline
\end{tabular}

Table no 3: Formulation of diagnosis of halitosis

\begin{tabular}{|l|}
\hline Data collected from the patient history \\
Review the patient's chief complaint and history of present illness \\
Review the patients past history \\
Review the patients current history (investigate diet and medications) \\
\hline Findings on physical examination \\
Extra-oral examination \\
Intra oral examination \\
\hline Information provided from tests or special studies \\
Radiograph \\
Microbial cultures and sensitivity studies \\
Findings and diagnoses of consultants \\
\hline
\end{tabular}


Table no.4: Scores of Organoleptic Scale

\begin{tabular}{|l|l|}
\hline Organoleptic Scale (0-5). & $3=$ moderate odor \\
\hline $0=$ no appreciable odor & $4=$ strong odor \\
\hline $1=$ barely noticeable odor & $5=$ extremely foul odor \\
\hline $2=$ slight but noticeable odor & \\
\hline
\end{tabular}

Table no.5: Effect of various mouth washes on halitosis

\begin{tabular}{|l|l|}
\hline \multicolumn{1}{|c|}{ Method } & Effectiveness in reduction of oral malodor \\
\hline Rinsing with water & Effective for 15 minutes \\
\hline Use of sanguinarine rinses & No detectable decrease have been detected \\
\hline Essential phenolic oils & $\begin{array}{l}\text { Low substantivity and only transient } \\
\text { antibacterial effects but measurable reduction }\end{array}$ \\
\hline Zinc chloride rinses & Marked reduction of VSCs level \\
\hline Two phase mouthwashes & $\begin{array}{l}\text { Oil,water and cetylpyridinium chloride found } \\
\text { very effective at full strength }\end{array}$ \\
\hline Chlorhexidine & $\begin{array}{l}\text { Substantive antimicrobial agent,effective against } \\
\text { both gram negative and gram positive bacterial } \\
\text { species }\end{array}$ \\
\hline Chlorine dioxide & $\begin{array}{l}\text { No research to show efficacy or long term } \\
\text { effects }\end{array}$ \\
\hline Cetylpyridinium chloride & Shown to reduce VSC production for three hours \\
\hline
\end{tabular}

\section{REFERENCES}

[1] Rosenberg M. Bad breath: Research perspectives. Tel Aviv, Israel, Ramot Publishing,Tel Aviv University,1995,1-12.

[2] A. Tangerman, Halitosis in medicine: A review, International Dental Journal, 52, 2002, 201-206.

[3] K. Yaegaki, J. M. Coil, Clinical dilemmas posed by patients with psychosomatic halitosis. Quintessence International, 30, 1999, 328333

[4] C. Scully, M. Rosenberg. Halitosis, Dent Update, 30, 2003, 205-210

[5] I. Kleinberg, M. Codipilly, Modeling of oral malodor system and methods of analysis, Quintessence International, $30,1999,357-368$

[6] K. L Vandana, A Sridhar, Oral malodor: a review, Journal of Clinical and Diagnostic Research,2, 2008,768-773.

[7] K Yaegaki , K. Sanada, Biochemical and Clinical Factors influencing oral malodor in periodontal patients, Journal of Periodontol,63, 1992, 783-789.

[8] M Morita, H. Wang, Association between oral malodor and adult periodontitis: a review, Journal of Clincal Periodontol, 28, 2001,813-819.

[9] P Lu Dominic, Halitosis: An etiologic classification, a treatment approach and prevention,Journal of Oral Surgery Oral Medicine Oral Pathology 54(5), 1982, 521-526.

[10] J. D. McDowell, K Denise, Diagnosis and treating halitosis, Journal of American Dental Association 124,1993,55-64.

[11] M. Rosenberg, Clinical assessment to bad breath: current concepts, Journal of American Dental Association 127, 1996, 475-482

[12] M.Tanaka, H.Anguri, A. Nonaka, Clinical assessment of oral malodor by the electronic nose system, Journal of Dent Research, 83(4), 2004, 317-320

[13] A. Bosy, Oral malodor: philosophical and practical aspects, Journal of the Canadian Dental Association, 63, 1997, $196-201$. 